\title{
Innvandreres bruk av fastlegeordningen
}

\author{
Tilgang til helsetjenester og informasjon er grunnleggende for både \\ innvandrere og norskfødte personer. Det økende mangfoldet i befolk- \\ ningen er en utfordring for systemet og krever tilrettelagt informasjon.
}

Fastlegeordningen ble introdusert i 2001. Dette pasientlistesystemet tar sikte på å forbedre kvaliteten på tjenester levert av allmennleger ved blant annet å sikre kontinuitet i lege-pasient-relasjonen. - Etter hvert som mangfoldet i befolkningen øker, må tilgjengeligheten til helsetjenester overvåkes, forteller Ursula Småland Goth.

Ursula Småland Goth tar i sin avhandling for seg innvandrernes tilgang til fastlegeordningen. Arbeidet kombinerer to kvalitative og en kvantitativ studie. De kvalitative dataene er basert på intervjuer med fastleger i Oslo samt på nøkkelinformanter fra innvandrerorganisasjoner. De belyser tilgjengeligheten av fastlegeordningen og danner grunnlaget for modellen som testes i den kvantitative delen. Kvantitative data er hentet fra konsultasjonsregisteret (Nav) for årene 2006 og 2007 og definert for de 15 største gruppene. For sammenliknbarhet er kun data fra Oslo inkludert. De forklarende faktorene testet i modellen er alder, kjønn, botid i Norge og fødeland.
- Resultatene viser et mangfoldig bruksmønster av helsetjenesten for nyankomne utenlandsfødte innbyggere mellom og innenfor de forskjellige minoritetsgrupper, sier hun. - Botid har vesentlig innflytelse på sannsynligheten for å kontakte legevakten, og informasjon om fastlegeordningen og den tildelte fastlege blir ikke korrekt oppfattet. Innvandrere som nylig har kommet til Norge, får ofte lite informasjon om organiseringen av helsesektoren og er uvitende om hvilken fastlege de tilhører.

Det sentrale resultatet fra denne studien er at svært mange ikke blir gitt informasjon, verken i personlig møte med legen eller på en forståelig måte. Dette kan forklare hvorfor mange nyankomne innvandrere søker hjelp på legevaktens akuttmottak fremfor hos fastlegen, avslutter Goth.

\section{Ingrid Skinlo Rokstad}

ingrid.rokstad@legeforeningen.no

Tidsskriftet

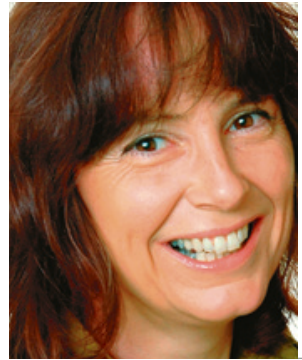

Ursula Småland Goth. Foto privat

Disputas

Ursula Småland Goth disputerte for ph.d.graden ved Oslo universitetssykehus, Ullevål 17.8. 2012. Tittelen på avhandling er Innvandreres bruk av fastlegeordningen.

\section{Riktig bruk av traumeteam}

\author{
Ved å bruke fullt traumeteam ved antatt alvorlig skade og begrenset \\ traumeteam ved antatt lettere skade begrenses underforbruk \\ av traumeteamet.
}

Prehospital triage brukes til å klassifisere pasientens skadeomfang. Ved mistanke om alvorlig skadet pasient tilkalles traumeteam til akuttmottak slik at rask behandling sikres. Disse traumeteamene er ressurskrevende og bør brukes riktig. Marius Rehn har i sin doktoravhandling bl.a. sett på pasienter innlagt ved Oslo universitetssykehus i en sjuårsperiode der enten traumeteam ble tilkalt eller pasienten ble skrevet ut med diagnose som tilsa gjennomgått traume.

- I $55 \%$ av tilfellene hvor traumeteamet ble tilkalt, var ikke pasienten alvorlig skadet, forteller Rehn. - Traumeeamet kunne bli tilkalt på grunnlag av synlig skade på pasient, ustabil pasient, på grunnlag av skademekanisme eller ved flere skadede. Overforbruk av traumeteam var hyppigst der hvor det var skademekanismen som utløste tilkalling av teamet. Av pasientene som var alvorlig skadet, ble $10 \%$ ikke behandlet av traumeteam. Ved denne underforbruken av traumeteamet var pasientene oftere eldre og hadde vært utsatt for fallulykker, utdyper han.

Ved Stavanger universitetssjukehus ble det i 2009 innført nivådelt traumeteam, hvor antatt lavrisikopasienter ble håndtert av et begrenset traumeteam, og fullt traumeteam ble forbeholdt pasienter med potensielt livstruende skader.

- Vi fant at denne systemendringen medførte lavere terskel for bruk av traumeteamet og at underforbruket ble redusert, forklarer Rehn. - Samtidig økte overforbruket av traumeteamet, men siden teamstørrelsen var mindre, medførte systemendringen en ressursbesparelse. Vi konkluderte med at nivådelt skadeomsorg øker pasientsikkerheten og reduserer ressursbruken, avslutter Rehn.

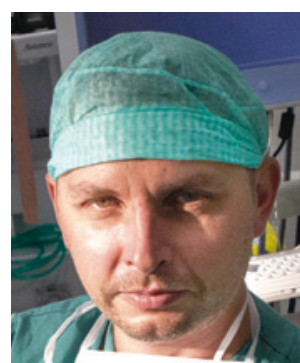

Marius Rehn

Foto Norsk luftambulanse

\section{Disputas}

Marius Rehn disputerte for ph.d.-graden ved Universitetet i Oslo 4.9. 2012. Tittelen på avhandlingen er Field triage of victims of trauma. Efficacy of trauma team activation protocols. 